\title{
Synergistic effect in conductive networks constructed with carbon nanofillers in different dimensions
}

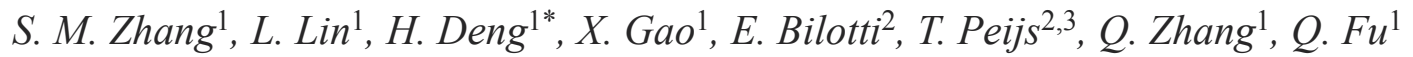 \\ ${ }^{1}$ College of Polymer Science and Engineering, State Key Laboratory of Polymer Materials Engineering, Sichuan \\ University, 610065 Chengdu, People's Republic of China \\ ${ }^{2}$ Queen Mary University of London, School of Engineering and Materials Science, and Centre of Materials Research, \\ Mile End Road, E1 4NS London, UK \\ ${ }^{3}$ Eindhoven University of Technology, Eindhoven Polymer Laboratories, 5600 MB Eindhoven, The Netherlands
}

\begin{abstract}
Herein, investigation on synergistic effect during network formation for conductive network constructed with carbon nanofillers in different dimensions is conducted. Multi-walled carbon nanotubes (MWNTs) and carbon black (CB) are employed as conductive fillers in this system. Morphological control of the conductive network is realized by adjusting the ratio between different fillers. Classical percolation threshold theory and adjusted excluded volume theory are used to analyze the electrical percolating behavior of these systems. It is observed that the percolation threshold of hybrid fillers filled conductive polymer composites (CPCs) is much lower than that of MWNTs or CB filled CPCs, and it can be reduced from 2.4 to $0.21 \mathrm{wt} \%$ by replacing half of the MWNTs with CB. Possible mechanism of this phenomenon is discussed together with morphological observation. A model is proposed to understand the mechanism of the percolation behavior in the composites containing various proportions of nanofillers. Our work is important for the design and preparation of low cost conductive polymer composites with novel electrical property.
\end{abstract}

Keywords: nanocomposites, carbon nanotubes, carbon black, synergistic effect, electrical percolation

\section{Introduction}

Conductive polymer composites ( $\mathrm{CPCs}$ ) have attracted a lot of attention in the past few decades, and have many potential applications including antistatic [1], electromagnetic interference shielding [2], sensing [3-8], flexible solar cell electrodes [9], field emission $[10,11]$, etc. CPCs can be fabricated by adding conductive filler into an insulating polymer matrix, where a sudden jump in conductivity can be observed while a critical content of filler is incorporated. Classic percolation theory is often used to describe such a phenomenon [12], and carbon nanotubes (CNTs), carbon black (CB), graphite, graphene nanoplates etc. are often used as electrically conductive fillers. CNTs are believed to be one of the most interesting conductive fillers due to their ultra-high aspect ratio and intrinsic conductivity [13-17]. For example, the percolation threshold of CPCs containing CNTs can be as low as $0.0025 \mathrm{wt} \%$ [18-21]. In these systems, percolation thresholds are significantly lower than $0.1 \mathrm{wt} \%$. It is attributed to the kinetic percolation which allows for particle movement and re-aggregation [22], and these results are often achieved in emulsion or solution-based systems under controlling the viscosity of the aqueous composite mixture and the shear intensity of the stirring process. However, percolation threshold is often much higher for composites prepared by melt compounding. McNally et al. [23] observed a percolation threshold of $7.5 \mathrm{wt} \%$ for

\footnotetext{
${ }^{*}$ Corresponding author, e-mail: huadeng@scu.edu.cn
} (c) BME-PT 
PE/MWNTs composites prepared by melt blending. The value is often between 1 to $5 \mathrm{wt} \%$ for melt compounded systems and considered as statistical percolation threshold [22]. The mechanism behind this significant difference between kinetic and statistical percolation is the prohibition of re-aggregation between CNTs during melt compounding process $[22,24]$. It was reported that the re-aggregation process of CNTs within polymer melt can take hours to complete [25].

To achieve better conductivity or lower cost, more than one kind of filler, particularly fillers in different aspect ratios, are used to prepare CPCs. Regarding the formation of conductive network with fillers in different aspect ratios, theoretical study has shown that it is not necessary to build conductive network with high aspect ratio filler alone [26], and the percolation threshold is sensitive to the portion of high aspect ratio filler in a system containing fillers in different aspect ratios [27]. There are a number of investigations reported in the literature on mixed carbon fillers filled CPCs [26, 28-31]. However, the percolation thresholds of these systems filled with mixed fillers are only simple average of that for systems filled with a particular kind of carbon filler. Therefore, more study is needed to study the true synergistic effect between conductive fillers of different dimensionality in building conductive network.

In current study, CPCs based on mixed filler between carbon nanofillers in different dimensions and polypropylene will be fabricated. It is well known that polyolefin is a widely used material and its processability is prominent. Moreover, due to the difference in filler dimension and intrinsic structure, the networks formed with mixed fillers might illustrate interesting percolating behavior in CPCs. Furthermore, this study could be used as an example to demonstrate the real synergistic effect between different dimensional fillers and replace high price and aspect ratio filler with lower ones. Multiwall carbon nanotubes (MWNTs) and CB will be used as conductive fillers. Classical percolation threshold theory and adjusted excluded volume theory [26] will be used to analyze the electrical percolating behavior of current systems.

\section{Experimental}

\subsection{Materials}

MWNTs (NC 7000, Nanocyl S.A., Belgium) were used for the preparation of CPCs. These MWNTs have an outer diameter of $10 \mathrm{~nm}$, a length of $1.5 \mu \mathrm{m}$, and a surface area of $250-300 \mathrm{~m}^{2} \cdot \mathrm{g}^{-1}$ according to the producer. CB (VXC-605, Cabot Co. Ltd, U.S.) is acetylene carbon black with DBP absorption of $148 \mathrm{~cm}^{3} / 100 \mathrm{~g}$, and a primary particle diameter of $34 \mathrm{~nm}$. A maleic anhydride grafted polypropylene (PP-g-MA) (E43, Westlake Chemical, U.S.) was used as compatibilizer. Polypropylene (PP, Basell Adsyl 5C39F, Basell, U.S. $)$ is a copolymer $\left(M_{\mathrm{w}}=\right.$ $320 \mathrm{~kg} \cdot \mathrm{mol}^{-1}$, MFI $=5.5 \mathrm{~g} \cdot \mathrm{min}^{-1}$ ) containing $98 \%$ of PP and $2 \%$ of ethylene.

\subsection{Composites preparation}

Fillers were melt-blended with PP copolymer (coPP) in an internal mixer (XSS-300, Qingfeng Mould Factory, Shanghai, China) at $200^{\circ} \mathrm{C}, 100 \mathrm{rpm}$ for $15 \mathrm{~min}$ in order to prepare the masterbatch with high filler content. The mixture of MWNT and CB are mentioned as 'Hybrid fillers' in the following. Then, the masterbatch, co-PP and E43 were added into a double-screw micro-extruder (HAAKE MiniLab, Thermo Electron, Germany) at $200^{\circ} \mathrm{C}, 100 \mathrm{rpm}$ for $15 \mathrm{~min}$ to prepare composites containing different filler content. The content of E43 is kept at $10 \mathrm{wt} \%$ for all composites in this study. The extruded strand was then cut and hot-pressed (KT-0701, Kangte Technology Co. Ltd, Beijing, China) into a film with a thickness about $200 \mu \mathrm{m}$ at $200^{\circ} \mathrm{C}, 20 \mathrm{MPa}$ for $5 \mathrm{~min}$.

\subsection{Composites characterization}

\subsubsection{Electrical measurements}

Direct current (DC) electrical resistivity is measured for the composites at different processing stages. Two points method was used. To avoid contact resistance, silver paint was applied on both ends of the tape. As a result, contact resistance is negligible compared to sample resistance. The resistance is measured by a Keithley 6487 picoammeter (Keithley Instruments Inc. Ohio, USA) at a constant voltage of $1 \mathrm{~V}$. The results were recorded after the voltage had been exerted for 5 seconds. Resistivity can be calculated using the resistance by Equation (1): 
$\rho=\frac{R \cdot w \cdot t}{l}$

where $R$ is the resistance of the sample, $w, t$, and $l$ represent width, thickness and length of the sample, respectively. Resistivity exceeding $10^{4} \Omega \cdot \mathrm{m}$ is not measurable with the current set-up and these films are therefore classified as non-conductive.

\subsubsection{Scanning electron microscope (SEM)}

Morphology studies were carried out on a scanning electron microscope (SEM, Inspect F, FEI company, USA) under an acceleration voltage of $20 \mathrm{kV}$. For the investigation of conductive networks, uncoated specimens were used. To study the morphology of network constructed with lower filler content, standard gold-coated specimens were used.

\section{Results and discussion}

\subsection{Percolation threshold in isotropic systems}

The electrical conductivity of isotropic nanocomposites is plotted as a function of filler content in Figure 1. Composites containing only MWNTs, only $\mathrm{CB}$, both MWNTs and $\mathrm{CB}$ in the ratio of $1: 1,1: 4$ and 4:1 are labeled as: CPC-MWNT, CPC-CB,

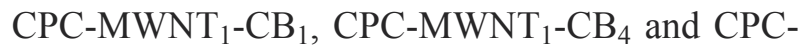
$\mathrm{MWNT}_{4}-\mathrm{CB}_{1}$, respectively. The result that the CPC$\mathrm{CB}$ system exhibits a higher percolation threshold than the CPC-MWNT system is anticipated due to the higher aspect ratio of MWNTs comparing with CB. Further experiments were carried out to investigate the influence of hybrid nanofillers and the ratio between them on the electrical percolating behavior. Interestingly, a measurable resistivity is

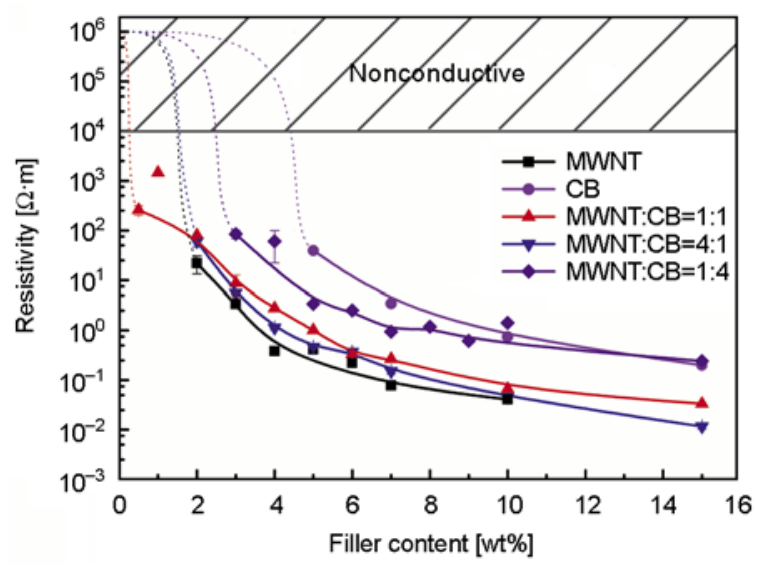

Figure 1. DC electrical resistivity of nanocomposites: $\mathrm{CPC}$ MWNT, CPC-CB, CPC-MWNT $1-\mathrm{CB}_{1}, \mathrm{CPC}-$ $\mathrm{MWNT}_{4}-\mathrm{CB}_{1}$ and $\mathrm{CPC}-\mathrm{MWNT}_{1}-\mathrm{CB}_{4}$. Please note that the dot lines are drawn to guide the eye. obtained for the composites containing a hybrid filler consisting of $0.25 \mathrm{wt} \%$ MWNTs and $0.25 \mathrm{wt} \%$ $\mathrm{CB}$, while the resistivity of the composites filled with MWNTs alone could only become conductive for the filler contents above $2 \mathrm{wt} \%$. Therefore, the percolation threshold is reduced significantly by using a hybrid nanofiller system. As shown in Figure 1, $\mathrm{CPC}-\mathrm{MWNT}_{1}-\mathrm{CB}_{1}$ are more conductive than CPC-MWNT ${ }_{1}-\mathrm{CB}_{4}$ at the same total filler content. Furthermore, the resistivity of the composites containing hybrid nanofillers is higher than CPCMWNT at the same filler content. However, the resistivity of CPC-MWNT $-\mathrm{CB}_{1}$ and CPC-MWNT ${ }_{1}-\mathrm{CB}_{1}$ is very close to that of CPC-MWNT. Therefore, the synergistic effect between $\mathrm{CB}$ and MWNTs allows the partial replacement of high aspect ratio and high priced nanofillers (MWNTs) with low aspect ratio, low priced fillers (CB) in CPCs. This agrees well with the theoretical results reported in literature [27]. More importantly, the synergistic effect between $\mathrm{CB}$ and MWNTs results in a reduced percolation threshold for CPC-MWNT ${ }_{1}-\mathrm{CB}_{1}$ compared with CPC-MWNT.

In order to perform a more in-depth analysis, the data of the above five systems were fitted according to the classical percolation scaling law, see Equation (2):

$\sigma=\sigma_{0}\left(P-P_{\mathrm{c}}\right)^{\mathrm{t}}$

for $P>P_{\mathrm{c}}$

where $\sigma_{0}$ is a scaling factor, $P_{\mathrm{c}}$ is the percolation threshold, $\sigma$ is the conductivity of the CPC and $P$ is the filler content in the CPC [12]. The exponent $t$ is a parameter which depends on the dimensionality of the conductive network. It is expected to vary for different materials with calculated values of $t \approx 1.3$ and $t \approx 2.0$ for two and three dimension networks, respectively. As widely reported in the literature [4, 32], the percolation threshold of CPCs can be determined accurately, and information on the dimensionality of the conducting network can be obtained through the fitting of classical percolation scaling law to experimentally obtained conductivity data. Hence, the percolation threshold $P_{\mathrm{c}}$ and exponent $\mathrm{t}$ are obtained, the results are shown in Figure 2.

Furthermore, excluded volume theory has been widely used in conductive polymer composites filled with one type of conductive filler to analyze their conductive percolation behavior [19, 24]. 

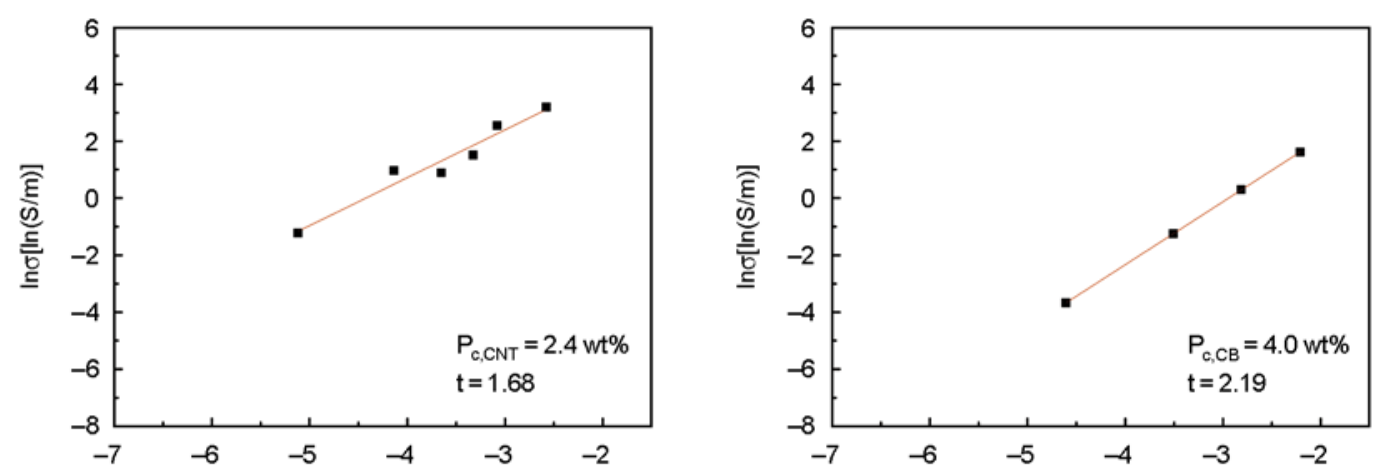

a)

b)
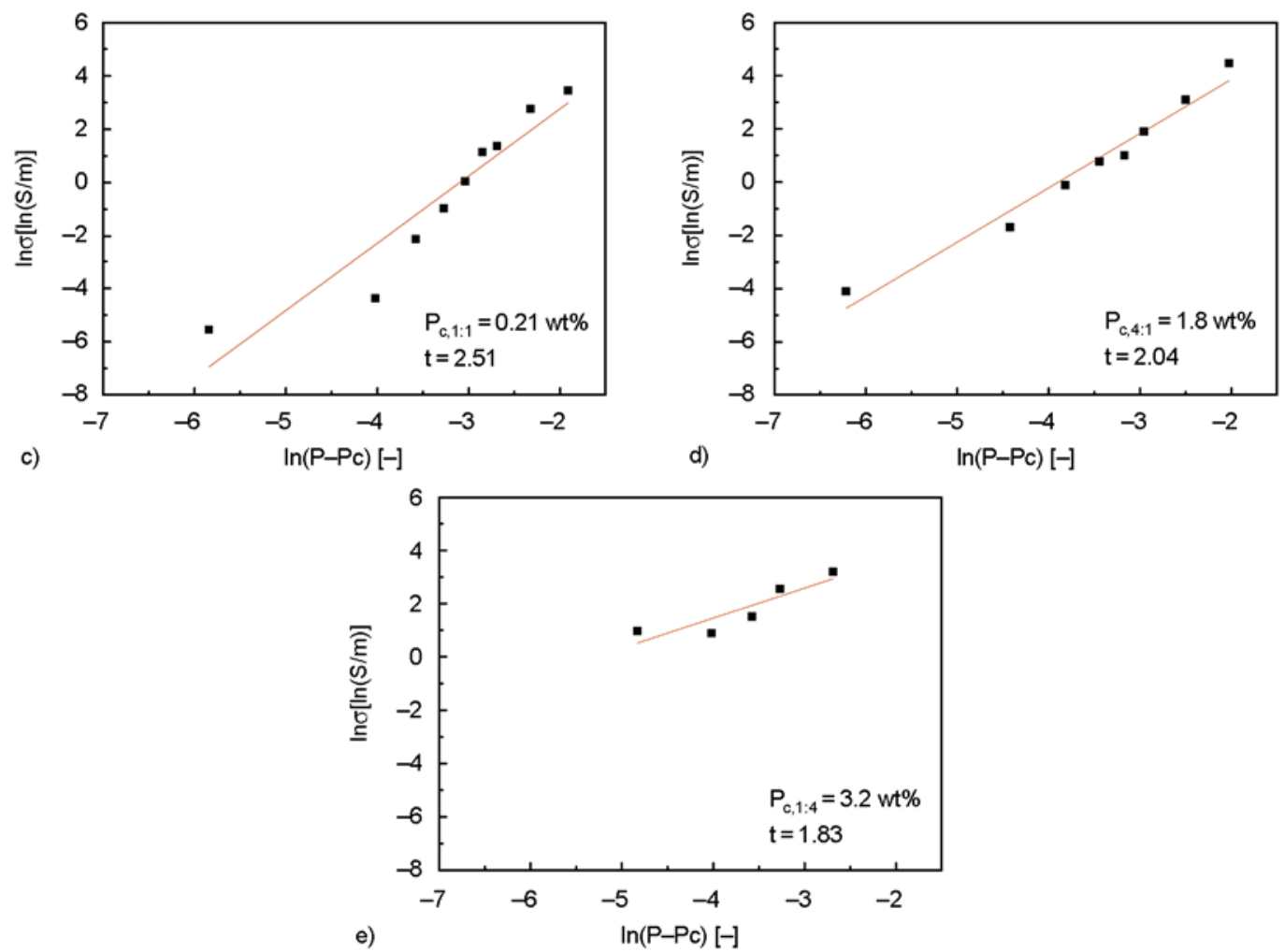

Figure 2. Plots of classical percolation threshold theory fitting of the composites: (a) CPC-MWNT; (b) CPC-CB; (c) CPC$\mathrm{MWNT}_{1}-\mathrm{CB}_{1}$; (d) CPC-MWNT $4-\mathrm{CB}_{1}$; (e) CPC-MWNT $-\mathrm{CB}_{4} . R^{2}$ of these curves are: (a) $R^{2}=0.94$; (b) $R^{2}=$ 1.00 ; (c) $R^{2}=0.87$; (d) $R^{2}=0.96$; (e) $R^{2}=0.73$.

Recently, it is reported that the percolation threshold of ternary systems containing two types of conductive fillers can be estimated by using an equation derived from the excluded volume approach [26, 29, 33] (Equation (3)):

$$
\frac{m_{\mathrm{CNT}}}{P_{\mathrm{c}, \mathrm{CNT}}}+\frac{m_{\mathrm{CB}}}{P_{\mathrm{c}, \mathrm{CB}}}=1
$$

where $m_{\mathrm{CNT}}$ and $m_{\mathrm{CB}}$ are the mass fraction in the ternary systems, $P_{\mathrm{c}, \mathrm{CNT}}$ and $P_{\mathrm{c}, \mathrm{CB}}$ are the percolation thresholds in the binary systems for CNT and CB, respectively. Therefore, the theoretical percolation threshold of the binary systems can be calculated using Equation (3). Using the system of CPC$\mathrm{MWNT}_{1}-\mathrm{CB}_{1}$ as an example, it is possible to calculate the filler content of each particle for the ternary system using Equation (4) taking into account the percolation threshold of the binary systems shown in Figure 2:

$m_{\mathrm{CNT}}=m_{\mathrm{CB}}=1.5 \mathrm{wt} \%$

Thus, the theoretical percolation threshold of the ternary system is calculated as shown in Equation (5):

$P_{\mathrm{c}, 1: 1}=2 m_{\mathrm{CNT}}=2 m_{\mathrm{CB}}=3.0 \mathrm{wt} \%$ 


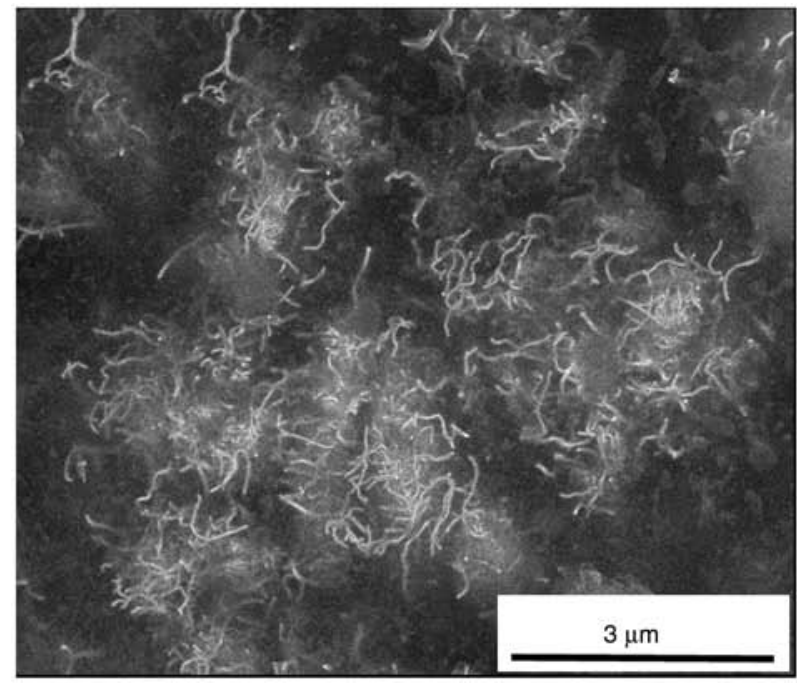

a)

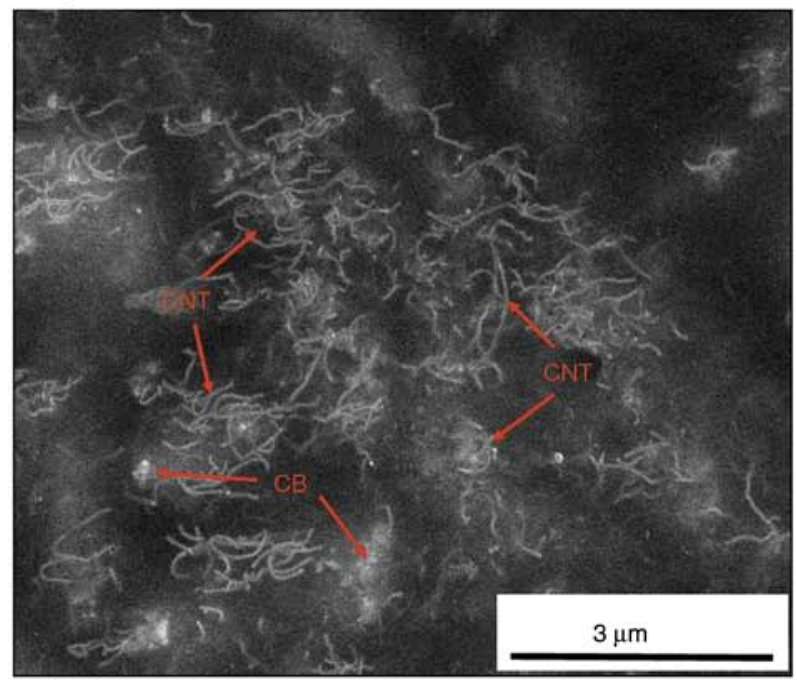

c)

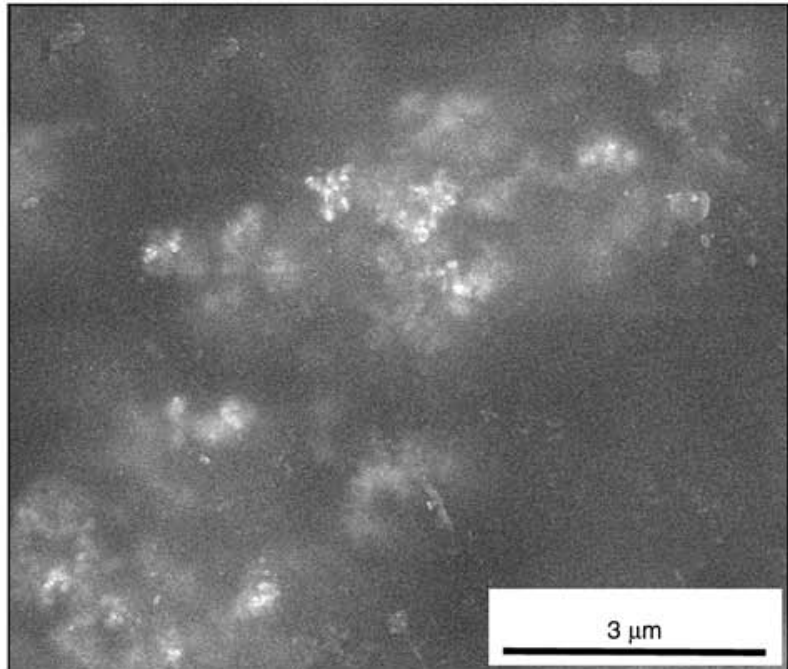

b)

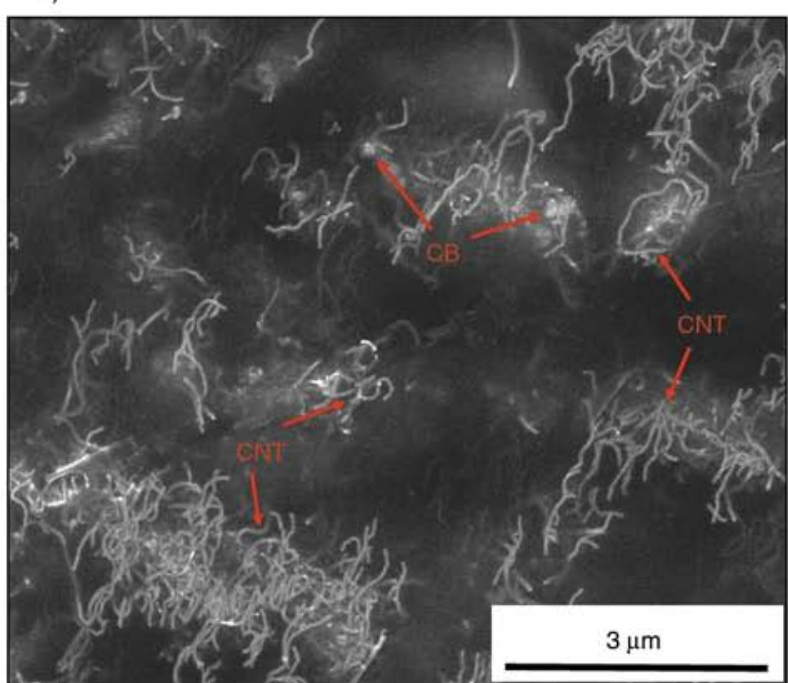

d)

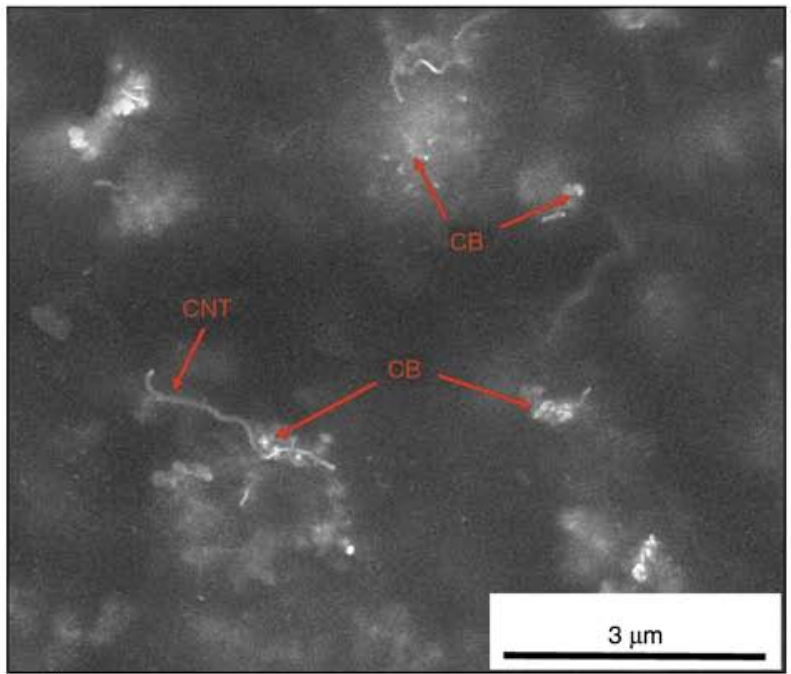

e)

Figure 3. SEM micrographs of isotropic CPCs: (a) MWNTs $(10 \mathrm{wt} \%) / \mathrm{E} 43 / \mathrm{co}-\mathrm{PP}$; (b) CB (10 wt $\%) / \mathrm{E} 43 / \mathrm{co}-\mathrm{PP}$; (c) MWNTs $(5 \mathrm{wt} \%) / \mathrm{CB}(5 \mathrm{wt} \%) / \mathrm{E} 43 / \mathrm{co}-\mathrm{PP}$; (d) MWNTs $(8 \mathrm{wt} \%) / \mathrm{CB}(2 \mathrm{wt} \%) / \mathrm{E} 43 / \mathrm{co}-\mathrm{PP}$; (e) MWNTs $(2 \mathrm{wt} \%) / \mathrm{CB}(8 \mathrm{wt} \%) / \mathrm{E} 43 / \mathrm{co}-\mathrm{P}$ 
An obvious difference can be observed between the experimental percolation threshold $(0.21 \mathrm{wt} \%)$ and calculated theoretical one $(3.0 \mathrm{wt} \%)$ for $\mathrm{CPC}$ $\mathrm{MWNT}_{1}-\mathrm{CB}_{1}$. Unlike reported in previous literature [29], the difference between experimental percolation threshold $(0.5 \mathrm{wt} \%)$ and the theoretical one $(3.0 \mathrm{wt} \%)$ is rather obvious. As discussed above, a measurable resistivity is obtained in MWNTs $(0.25 \mathrm{wt} \%) / \mathrm{CB}(0.25 \mathrm{wt} \%) / \mathrm{E} 43 / \mathrm{co}-\mathrm{PP}$ while the resistivity of the composites filled with MWNTs alone could only become conductive for the filler contents above $2 \mathrm{wt} \%$, thus, a statement on the presence of synergistic effect in percolation dynamics in such a system can be made. As revealed in Figure 3, MWNTs and CB are evenly dispersed in the polymer matrix and the electrical pathways are coformed by MWNTs and CB. Additionally, $P_{\mathrm{c}, 4: 1}$ and $P_{\mathrm{c}, 1: 4}$ can be calculated using the same method as 2.6 and $3.5 \mathrm{wt} \%$, respectively. Both of them are similar with the experimental values shown in Figure $2(1.8$ and $3.2 \mathrm{wt} \%)$. This indicates that there is no synergistic effect in $\mathrm{CPC}-\mathrm{MWNT}_{4}-\mathrm{CB}_{1}$ and CPC-MWNT ${ }_{1}-\mathrm{CB}_{4}$.

\subsection{Morphology of the composites}

To understand the synergistic effect between MWNTs and CB, SEM was carried out to investigate the morphology of the composites with different filler contents and proportions. High accelerating voltage is applied to give enriched secondary electrons to perform voltage contrast imaging as demonstrated in literature [34-36]. Figure $3 \mathrm{a}$ and $3 \mathrm{~b}$ shows the

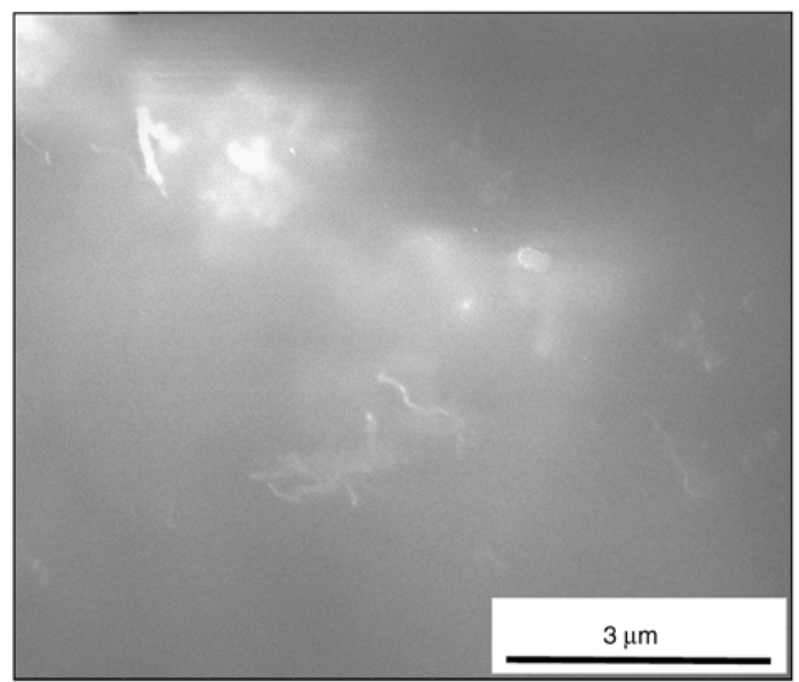

a)

Figure 4. SEM image for CPCs containing a total filler content of $0.5 \mathrm{wt} \%$ (a) $\mathrm{CPC}-\mathrm{MWNT}_{1}-\mathrm{CB}_{1}$ (b) a representative picture of CPC-MWNT 4 - $\mathrm{CB}_{1}, \mathrm{CPC}-\mathrm{MWNT}_{1}-\mathrm{CB}_{4}, \mathrm{CPC}-\mathrm{MWNT}$ and $\mathrm{CPC}-\mathrm{CB}$ morphology of the conductive network formed by MWNTs and CB, respectively, and Figure 3c, 3d and $3 \mathrm{e}$ shows that of hybrid fillers, where the bright phase is conductive filler and the black background is co-PP matrix.

As shown in Figure 3, isotropic conductive networks are obtained in the composites for the conductive networks formed by MWNTs and CB. Because of the high aspect ratio and fibrous shape, MWNTs filled composite showed such a network that MWNTs are entangled to form conductive pathways. However, the network formed by CB is obviously different from that formed by MWNTs as CB is a three dimensional, sphere shaped filler. And the conductive pathway was formed through the aggregations of CB particles. It is noted that the conductive networks formed with mixed fillers (see Figure 3) demonstrate a complex nanostructure of multiple MWNTs bridging adjacent CB particles. Since the natural structure and proportions of the fillers in ternary system are different, the morphology displays diverse features.

Since these CPCs demonstrate interesting electrical percolation behavior while hybrid fillers are contained. More SEM study is carried out to further investigate their morphology. Figure $4 \mathrm{a}$ shows the morphology for CPCs containing $0.25 \mathrm{wt} \%$ MWNTs and $0.25 \mathrm{wt} \% \mathrm{CB}$. It is noted that clear conductive network can be observed, nevertheless, no network can be observed in the representative picture from CPCs containing $0.5 \mathrm{wt} \%$ hybrid filler (MWNTs:CB) in the ratio of: $4: 1,1: 4,5: 0,0: 5$. This further con-

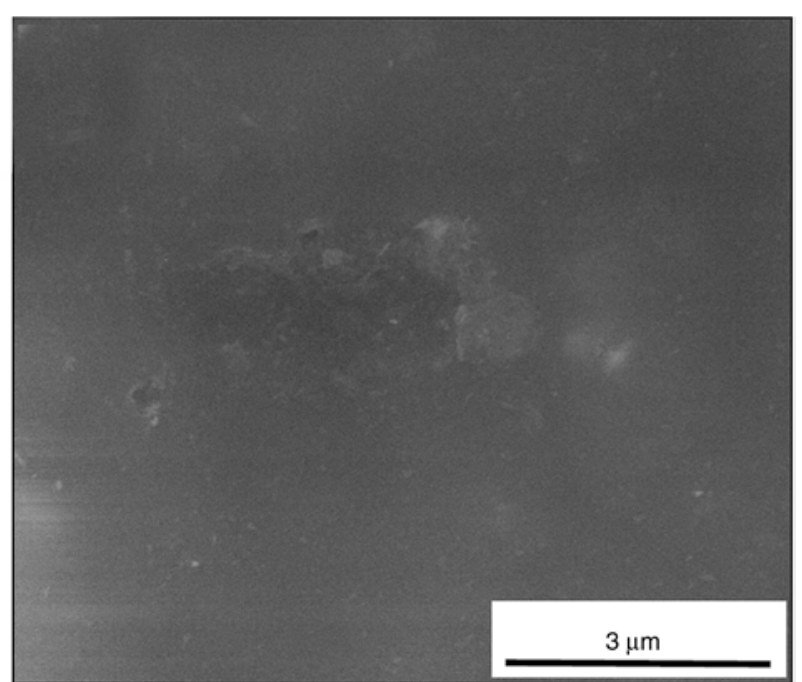

b) 


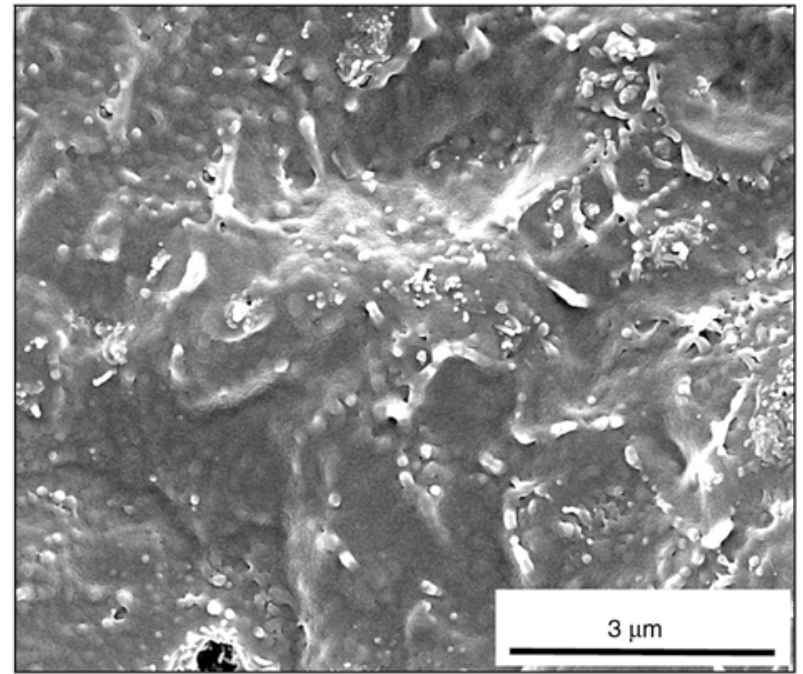

a)

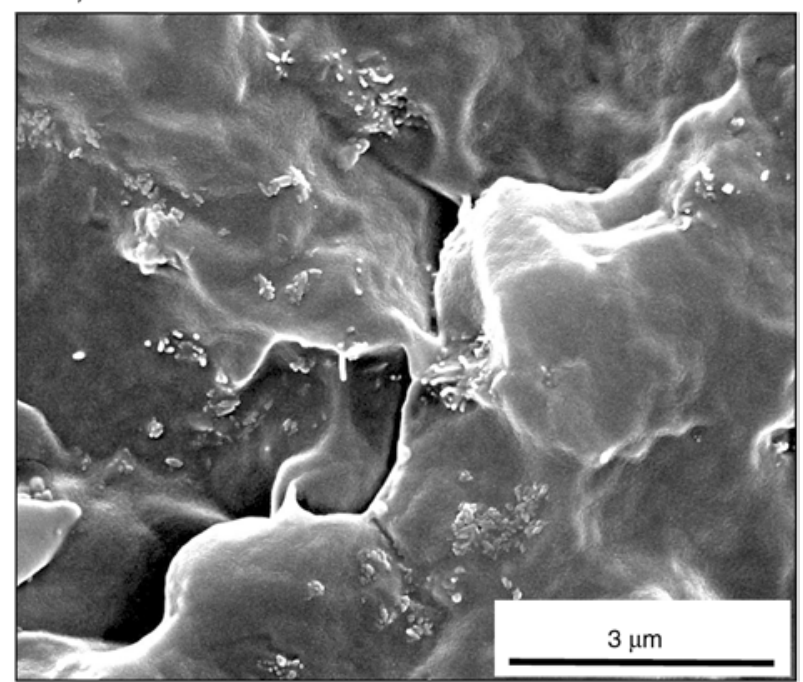

b)

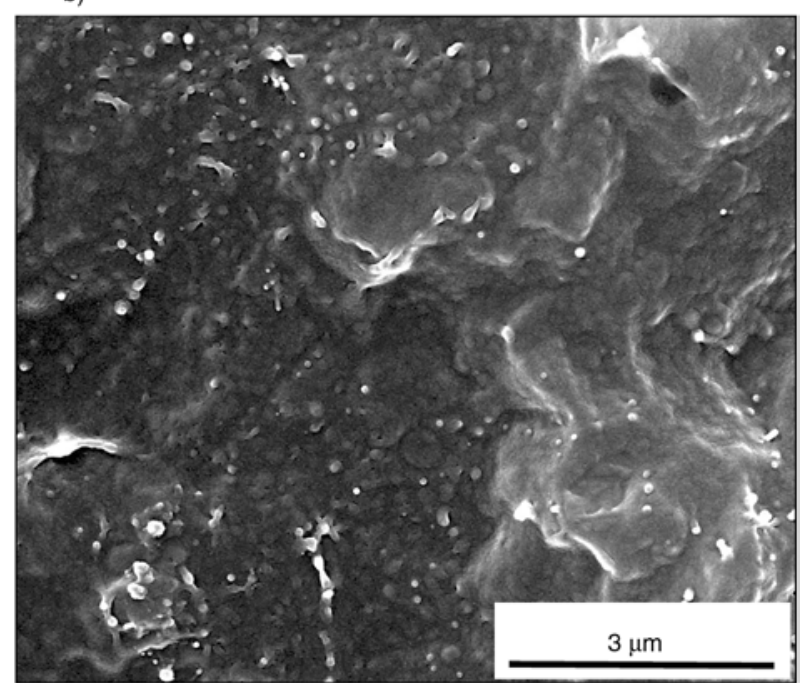

c)

Figure 5. Fracture surface of CPCs containing $0.5 \mathrm{wt} \%$ of hybrid filler, (a) CPC-MWNT $-\mathrm{CB}_{1}$, (b) CPC$\mathrm{MWNT}_{4}-\mathrm{CB}_{1}$ and (c) CPC-MWNT $-\mathrm{CB}_{4}$ firms the presence of conductive network in the CPCs containing $0.25 \mathrm{wt} \%$ MWNTs and $0.25 \mathrm{wt} \%$ $\mathrm{CB}$, and the absence of that in the rest, as non-conductive specimens are charged up during voltage contrast imaging in SEM [35, 36].

It is well known that MWNTs has higher conductivity than CB. Nevertheless, it is observed that the no measurable conductivity is obtained for CPC$\mathrm{MWNT}_{4}-\mathrm{CB}_{1}$ and $\mathrm{CPC}-\mathrm{MWNT}_{1}-\mathrm{CB}_{4}$ containing $0.5 \mathrm{wt} \%$ hybrid filler, while CPC-MWNT ${ }_{1}-\mathrm{CB}_{1}$ containing the same amount of hybrid filler is conductive, despite of the fact that less highly conductive MWNTs is contained comparing with CPC-MWNT $4^{-}$ $\mathrm{CB}_{1}$. To try to understand this, the morphology of the gold coated fracture surface of these CPCs containing hybrid fillers is investigated with SEM (see Figure 5). It is noted that MWNTs are more entangled in the CPCs containing more MWNTs. Similar effect is often observed in CNT/polymer composites [37]. Therefore, the extra MWNTs contained in CPC-MWNT ${ }_{4}-\mathrm{CB}_{1}$ are entangled in these bundles, and not being used to building up conductive networks effectively. This might be responsible for the effect observed.

\subsection{The mechanism of conductive network formation}

According to the observation and discussion above, the following mechanism is proposed to explain the electrical percolation behavior observed. Comparing CPC-CB with CPC-MWNT, a higher percolation threshold and higher resistivity are obtained in the former system. It is caused by the lower aspect ratio, lower specific surface area and higher intrinsic resistivity of $\mathrm{CB}$ comparing with MWNTs. Regarding the ternary systems containing both $\mathrm{CB}$ and MWNTs, co-supporting networks are formed with two types of fillers. For the CPCs containing low filler content (e.g. $0.5 \mathrm{wt} \%$, see Figure 6a, $6 \mathrm{~b}$, $6 \mathrm{c})$, conductive networks are obtained in $\mathrm{CPC}$ $\mathrm{MWNT}_{1}-\mathrm{CB}_{1}$ thanks to the bridges provides by $\mathrm{CB}$ to MWNTs local networks. For CPC-MWNT $4-\mathrm{CB}_{1}$, the MWNTs become more entangled, and not being efficiently used to build up conductive network. While for CPC-MWNT $1-\mathrm{CB}_{4}$, the amount of high aspect ratio filler is too low to build conductive networks. Therefore, $\mathrm{CPC}-\mathrm{MWNT}_{1}-\mathrm{CB}_{1}$ demonstrates much lower percolation threshold than the rest of the CPCs. 


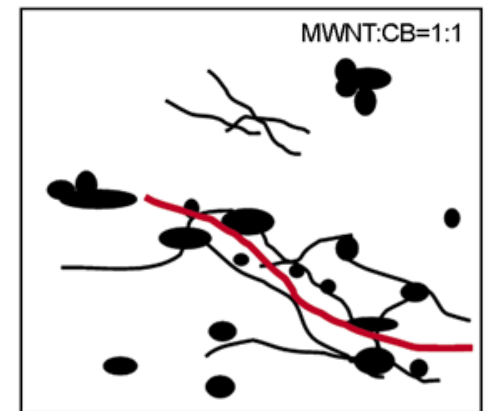

a)

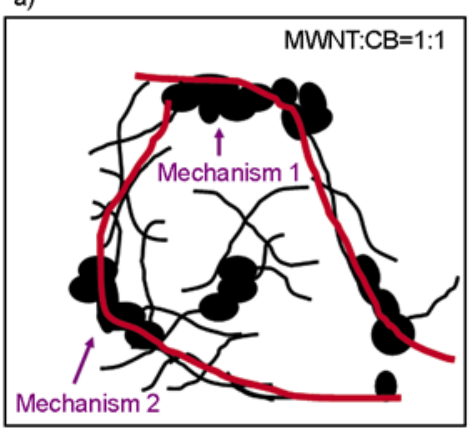

d)
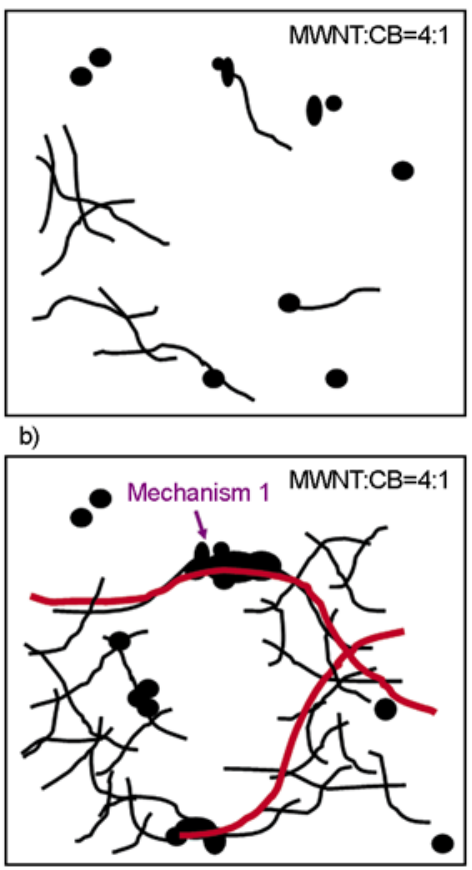

e)

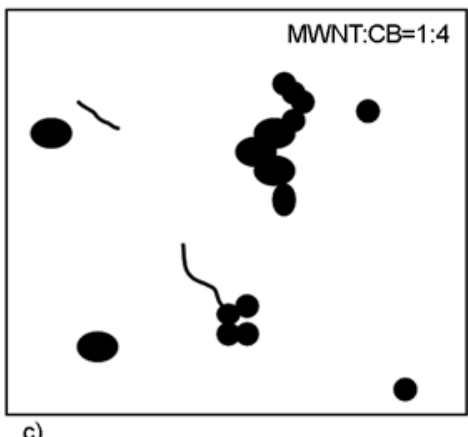

c)

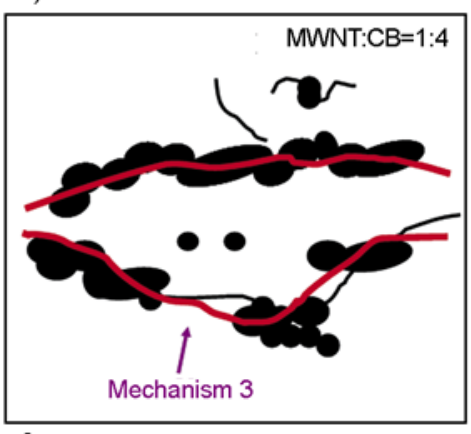

f)

Figure 6. Mechanism for the formation of conductive pathways by MWNTs and CB in ternary systems: (a, b, c) are composites filled with insufficient filler content; $(d, e, f)$ are composites filled with sufficient filler content

In the CPCs containing relative high filler content, the electrical resistivity is higher in the CPCs containing more MWNTs. This might be due to the fact that the conductive network is already established at these filler contents, therefore, CPC-MWNT ${ }_{1}^{-}$ $\mathrm{CB}_{1}$ is not demonstrating any synergistic effect in conductivity comparing with other CPCs. It is thought that there are three different mechanisms of conductive network formation in such a ternary system (see Figure 6d, 6e, 6f). Mechanism 1: shortcut of 'dead' network branches caused by new active branches of networks co-formed by CB [29]; mechanism 2: incorporation of $\mathrm{CB}$ into active 'MWNT' networks through bridging MWNT local networks with CB [29]; and mechanism 3: bridging local contacts between CB clusters through MWNTs. In the different ternary systems investigated in current study, mechanism 3 might be dominant in CPC$\mathrm{MWNT}_{1}$-CB4, as most of the conductive networks are formed by CB. Therefore, slightly higher resistivity is observed for these CPCs at higher filler content due to the higher intrinsic resistivity of $\mathrm{CB}$ comparing with MWNTs (see Figure 1). Mechanism 1 might dominate in $\mathrm{CPC}-\mathrm{MWNT}_{4}-\mathrm{CB}_{1}$, as most of the conductive networks are formed by MWNTs. As shown in Figure 6d, both mechanisms might occur simultaneously in CPC-MWNT ${ }_{1}-\mathrm{CB}_{1}$.

\section{Conclusions}

With the effort to partially replace high price filler (MWNTs) with lower ones (such as CB), a melt processing based method is used to fabricate CPCs filled with carbon nanofillers in different dimensions: MWNTs and CB. Morphological difference of the conductive network formed by the nanofillers is observed due to difference in dimension between these fillers. Moreover, synergistic effect between carbon nanofillers is demonstrated in isotropic CPCs. The percolation threshold of hybrid fillers filled CPCs is much lower than that of MWNTs or CB filled CPCs, and it can be reduced from 2.4 to $0.21 \mathrm{wt} \%$ by replacing half of the MWNTs with $\mathrm{CB}$. Regarding the effect of different filler ratio, it is demonstrated that the lowest percolation threshold is observed while the ratio is $1: 1$. With increasing ratio, more entanglements between filler are observed in the system, this might be responsible for the increase percolation threshold. Nevertheless, the CPCs containing more MWNTs at filler content well above percolation are demonstrating lower resistivity despite of the filler ratio, this is thought to be caused by the fact that relative stable conductive network are already building at these filler contents. This work could provide interesting method for the preparation of low cost, high performance CPCs. 
Regarding future work, it would be interesting to investigate the effect of surface properties of carbon nanofillers on the synergistic effect observed, since the surface properties of $\mathrm{CB}$ is reported to be closely related with its electrical percolating behavior in CPCs [38]. This might give explanation for the difference between current study and the ones report in literature, where such a synergistic effect was not observed in similar systems [26, 29].

\section{Acknowledgements}

We express our sincere thanks to the National Natural Science Foundation of China for financial support (51003063, 51011130160, 50873063). We also would like to thank Prof. Z. M. Li for providing us with the carbon black used in this study.

\section{References}

[1] Deng H., Skipa T., Bilotti E., Zhang R., Lellinger D., Mezzo L., Fu Q., Alig I., Peijs T.: Preparation of highperformance conductive polymer fibers through morphological control of networks formed by nanofillers. Advanced Functional Materials, 20, 1424-1432 (2010). DOI: $10.1002 / \mathrm{adfm} .200902207$

[2] Ramasubramaniam R., Chen J., Liu H. Y.: Homogeneous carbon nanotube/polymer composites for electrical applications. Applied Physics Letters, 83, 29282930 (2003).

DOI: $\underline{10.1063 / 1.1616976}$

[3] Thostenson E. T., Chou T-W.: Carbon nanotube networks: Sensing of distributed strain and damage for life prediction and self healing. Advanced Materials, 18, 2837-2841 (2006).

DOI: 10.1002/adma.200600977

[4] Zhang R., Baxendale M., Peijs T.: Universal resistivitystrain dependence of carbon nanotube/polymer composites. Physical Review B, 76, 195433/1-195433/5 (2007).

DOI: 10.1103/PhysRevB.76.195433

[5] Gao L. M., Thostenson E. T., Zhang Z., Chou T-W.: Sensing of damage mechanisms in fiber-reinforced composites under cyclic loading using carbon nanotubes. Advanced Functional Materials, 19, 123-130 (2009).

DOI: $10.1002 / \mathrm{adfm} .200800865$

[6] Bouvree A., Feller J-F., Castro M., Grohens Y., Rinaudo M.: Conductive polymer nano-bioComposites (CPC): Chitosan-carbon nanoparticle a good candidate to design polar vapour sensors. Sensors and Actuators B: Chemical, 138, 138-147 (2009).

DOI: $10.1016 /$ j.snb.2009.02.022
[7] Feller J. F., Langevin D., Marais S.: Influence of processing conditions on sensitivity of conductive polymer composites to organic solvent vapours. Synthetic Metals, 144, 81-88 (2004).

DOI: $10.1016 /$ j.synthmet.2004.02.006

[8] Castro M., Lu J., Bruzaud S., Kumar B., Feller J-F.: Carbon nanotubes/poly( $\varepsilon$-caprolactone) composite vapour sensors. Carbon, 47, 1930-1942 (2009).

DOI: $10.1016 /$ j.carbon.2009.03.037

[9] Tae Kim A., Kim H. S., Lee S. S., Park M.: Singlewalled carbon nanotube/silicone rubber composites for compliant electrodes. Carbon, 50, 444-449 (2012). DOI: $10.1016 /$ j.carbon.2011.08.070

[10] Connolly T., Smith R. C., Hernandez Y., Gun'ko Y., Coleman J. N., Carey J. D.: Carbon-nanotube-polymer nanocomposites for field-emission cathodes. Small, 5, 826-831 (2009). DOI: $10.1002 / \mathrm{smll} .200801094$

[11] Alexandrou I., Kymakis E., Amaratunga G. A. J.: Polymer-nanotube composites: Burying nanotubes improves their field emission properties. Applied Physics Letters, 80, 1435-1437 (2002).

DOI: $10.1063 / 1.1449537$

[12] Stauffer D., Aharony A.: Introduction to percolation theory. Taylor and Francis, London (1994).

[13] Li Z., Luo G., Wei F., Huang Y.: Microstructure of carbon nanotubes/PET conductive composites fibers and their properties. Composites Science and Technology, 66, 1022-1029 (2006).

DOI: $10.1016 /$ j.compscitech.2005.08.006

[14] Martin C. A., Sandler J. K. W., Shaffer M. S. P., Schwarz M-K., Bauhofer W., Schulte K., Windle A. H.: Formation of percolating networks in multi-wall carbon-nanotube-epoxy composites. Composites Science and Technology, 64, 2309-2316 (2004).

DOI: $10.1016 /$ j.compscitech.2004.01.025

[15] Wang Q., Dai J., Li W., Wei Z., Jiang J.: The effects of CNT alignment on electrical conductivity and mechanical properties of SWNT/epoxy nanocomposites. Composites Science and Technology, 68, 1644-1648 (2008). DOI: 10.1016/j.compscitech.2008.02.024

[16] Zhang L., Wan C., Zhang Y.: Morphology and electrical properties of polyamide 6/polypropylene/multiwalled carbon nanotubes composites. Composites Science and Technology, 69, 2212-2217 (2009). DOI: $10.1016 /$ j.compscitech.2009.06.005

[17] Gao X., Zhang S., Mai F., Lin L., Deng Y., Deng H., $\mathrm{Fu}$ Q.: Preparation of high performance conductive polymer fibres from double percolated structure. Journal of Materials Chemistry, 21, 6401-6408 (2011). DOI: 10.1039/C0JM04543H

[18] Bryning M. B., Islam M. F., Kikkawa J. M., Yodh A. G.: Very low conductivity threshold in bulk isotropic single-walled carbon nanotube-epoxy composites. Advanced Materials, 17, 1186-1191 (2005).

DOI: $10.1002 / \mathrm{adma} .200401649$ 
[19] Sandler J. K. W., Kirk J. E., Kinloch I. A., Shaffer M. S. P., Windle A. H.: Ultra-low electrical percolation threshold in carbon-nanotube-epoxy composites. Polymer, 44, 5893-5899 (2003).

DOI: 10.1016/S0032-3861(03)00539-1

[20] Grunlan J. C., Mehrabi A. R., Bannon M. V., Bahr J. L.: Water-based single-walled-nanotube-filled polymer composite with an exceptionally low percolation threshold. Advanced Materials, 16, 150-153 (2004). DOI: 10.1002/adma.200305409

[21] Zhou Y. X., Wu P. X., Cheng Z-Y., Ingram J., Jeelani S.: Improvement in electrical, thermal and mechanical properties of epoxy by filling carbon nanotube. Express Polymer Letters, 2, 40-48 (2008).

DOI: $10.3144 /$ expresspolymlett.2008.6

[22] Bauhofer W., Kovacs J. Z.: A review and analysis of electrical percolation in carbon nanotube polymer composites. Composites Science and Technology, 69, 1486-1498 (2009).

DOI: 10.1016/j.compscitech.2008.06.018

[23] McNally T., Pötschke P., Halley P., Murphy M., Martin D., Bell S. E. J., Brennan G. P., Bein D., Lemoine P., Quinn J. P.: Polyethylene multiwalled carbon nanotube composites. Polymer, 46, 8222-8232 (2005). DOI: 10.1016/j.polymer.2005.06.094

[24] Deng H., Zhang R., Bilotti E., Loos J., Peijs T.: Conductive polymer tape containing highly oriented carbon nanofillers. Journal of Applied Polymer Science, 113, 742-751 (2009).

DOI: 10.1002/app.29624

[25] Alig I., Lellinger D., Dudkin S. M., Pötschke P.: Conductivity spectroscopy on melt processed polypropylene-multiwalled carbon nanotube composites: Recovery after shear and crystallization. Polymer, 48, 10201029 (2007). DOI: 10.1016/j.polymer.2006.12.035

[26] Sun Y., Bao H-D., Guo Z-X., Yu J.: Modeling of the electrical percolation of mixed carbon fillers in polymer-based composites. Macromolecules, 42, 459-463 (2009). DOI: $10.1021 / \mathrm{ma} 8023188$

[27] Otten R. H. J., van der Schoot P.: Continuum percolation of polydisperse nanofillers. Physical Review Letters, 103, 225704/1-225704/4 (2009).

DOI: 10.1103/PhysRevLett.103.225704

[28] Ma P-C., Liu M-Y., Zhang H., Wang S-Q., Wang R., Wang K., Wong Y-K., Tang B-Z., Hong S-H., Paik KW., Kim J-K.: Enhanced electrical conductivity of nanocomposites containing hybrid fillers of carbon nanotubes and carbon black. ACS Applied Materials and Interfaces, 1, 1090-1096 (2009).

DOI: $10.1021 / \mathrm{am} 9000503$
[29] Sumfleth J., Adroher X. C., Schulte K.: Synergistic effects in network formation and electrical properties of hybrid epoxy nanocomposites containing multiwall carbon nanotubes and carbon black. Journal of Materials Science, 44, 3241-3247 (2009).

DOI: $10.1007 / \mathrm{s} 10853-009-3434-7$

[30] Etika K. C., Liu L., Hess L. A., Grunlan J. C.: The influence of synergistic stabilization of carbon black and clay on the electrical and mechanical properties of epoxy composites. Carbon, 47, 3128-3136 (2009).

DOI: 10.1016/j.carbon.2009.07.031

[31] Feller J. F., Bruzaud S., Grohens Y.: Influence of clay nanofiller on electrical and rheological properties of conductive polymer composite. Materials Letters, 58, 739-745 (2004).

DOI: $10.1016 /$ j.matlet.2003.07.010

[32] Deng H., Bilotti E., Zhang R., Loos J., Peijs T.: Effect of thermal annealing on the electrical conductivity of high-strength bicomponent polymer tapes containing carbon nanofillers. Synthetic Metals, 160, 337-344 (2010).

DOI: 10.1016/j.synthmet.2009.11.001

[33] Balberg I., Anderson C. H., Alexander S., Wagner N.: Excluded volume and its relation to the onset of percolation. Physial Review B, 30, 3933-3943 (1984).

DOI: 10.1103/PhysRevB.30.3933

[34] Deng H., Zhang R., Reynolds C. T., Bilotti E., Peijs T.: A novel concept for highly oriented carbon nanotube composite tapes or fibres with high strength and electrical conductivity. Macromolecular Materials and Engineering, 294, 749-755 (2009).

DOI: $10.1002 /$ mame.200900151

[35] Loos J., Alexeev A., Grossiord N., Koning C. E., Regev O.: Visualization of single-wall carbon nanotube (SWNT) networks in conductive polystyrene nanocomposites by charge contrast imaging. Ultramicroscopy, 104, 160-167 (2005).

DOI: $10.1016 /$ j.ultramic.2005.03.007

[36] Li W., Buschhorn S. T., Schulte K., Bauhofer W.: The imaging mechanism, imaging depth, and parameters influencing the visibility of carbon nanotubes in a polymer matrix using an SEM. Carbon, 49, 19551964 (2011).

DOI: $10.1016 /$ j.carbon.2010.12.069

[37] Deng H., Bilotti E., Zhang R., Peijs T.: Effective reinforcement of carbon nanotubes in polypropylene matrices. Journal of Applied Polymer Science, 118, 30-41 (2010).

DOI: 10.1002/app.30783

[38] Pantea D., Darmstadt H., Kaliaguine S., Roy C.: Electrical conductivity of conductive carbon blacks: Influence of surface chemistry and topology. Applied Surface Science, 217, 181-193 (2003). DOI: $10.1016 / \mathrm{S} 0169-4332(03) 00550-6$ 